\title{
Estética do movimento e adestramento do olhar: considerações sobre o futebol brasileiro de mulheres
}

\author{
The Aesthetics of Movement and the Training of the Eye: \\ Considerations about the Brazilian Women Football
}

\author{
Talita Machado Vieira \\ Universidade Estadual Paulista (UNESP), Assis/Brasil \\ Doutoranda em Psicologia, Universidade Estadual Paulista \\ tmachadovieira@gmail.com
}

\begin{abstract}
Resumo: 0 presente artigo, de natureza teórico-conceitual, questiona os juízos de torcedores sobre o futebol de rendimento praticado por mulheres, qualificando-o como pouco estimulante e não atrativo. Propusemos o exame sobre como a categoria gênero colabora para tal avaliação, partindo do entendimento do futebol como fenômeno estético e buscando evidenciar o caráter relacional da experiência que se produz no encontro entre torcedor e partida. Procuramos identificar os elementos que influem na avaliação de uma partida como boa ou bela. Posteriormente, nos debruçamos sobre a noção de percepção e as condições que a afetam e produzem enquanto matrizes perceptivas, nos aproximando do conceito de habitus. À luz dessas considerações, concluímos que o habitus esportivo, particularmente o futebolístico, no caso do Brasil, revela, também, a presença de um habitus de gênero pautado na diferenciação entre seres humanos, sobretudo com base na morfologia corporal. Assim, podemos afirmar que o futebol praticado por mulheres não evoca, por si mesmo, uma experiência estética desagradável, mas convoca a ampliação das sensibilidades do torcedor para acolher outras formas de manifestação deste esporte.
\end{abstract}

PalaVRas-chave: Futebol de mulheres; Experiência estética; Percepção.

ABSTRACT: This article, of a theoretical-conceptual nature, questions the judgments of fans about the high-level soccer practiced by women, qualifying it as not stimulating and not attractive. We proposed examining how the gender category contributes to this evaluation, starting from the understanding of football as an aesthetic phenomenon and seeking to show the relational character of the experience that occurs in the encounter between the fans and the match. We tried to identify the elements that influence the evaluation of a match as good or beautiful. After that, we focus on the notion of perception and the conditions that affect and produce it as perceptive matrices, which lead us to the concept of habitus. As conclusion we pointed that the sport habitus, particularly soccer, in the brazilian context, also reveals the presence of a gender habitus based on the differentiation between human beings, mainly based on the body morphology. Thus, we can affirm that women's soccer does not, by itself, evince an unpleasant aesthetic experience, but it calls for an increase in the sensibilities of the fans to welcome other forms of manifestation of this sport.

KEYWoRDS: Women's Football; Aesthetic Experience; Perception. 


\section{INTRODUÇÃo ${ }^{1}$}

No cenário esportivo, o Brasil é popularmente definido e reconhecido como país do futebol. Tal afirmação se sustenta somente se preterirmos a diversidade de manifestações que a modalidade abriga em favor de uma de suas formas, a saber, o futebol de alto rendimento praticado por homens. Não raro, ouvimos, por exemplo, a alegação de que mulheres jogando futebol é algo que "não combina". Tal opinião é, frequentemente, expressa sem maior fundamentação por parte do avaliador que, desprovido dos recursos argumentativos necessários, limita-se a repetição da frase que, eventualmente, pode ser encerrada da seguinte maneira "não sei dizer o porquê, só sei que não combina".

O juízo que se faz sobre o futebol praticado por mulheres como algo sem graça, desengonçado, risível ou pouco estimulante nos revela aquilo que é apresentado pelo público, como uma das razões para a não adesão e popularização da modalidade entre os torcedores brasileiros. No cerne desta questão, porém, encontramos elementos residuais suficientes para sustentar uma discussão sobre as relações de gênero no referido esporte, considerando, aqui, o conjunto binário homem-mulher, tal qual se encontra em definições estritamente biológicas. Nossa abordagem se orientará pela consideração de que o testemunho dos torcedores expressa uma valoração estética sobre o futebol, a qual parece fundar-se como um problema que pode ser debatido a partir da percepção e do habitus, e que acaba por definir a exclusão das manifestações não correspondentes ao modelo que detém o monopólio sobre o gosto e o olhar da torcida.

\section{O CORPO EM MOVIMENTO NO FUTEBOL: ELEMENTOS PARA UMA APREENSÃO ESTÉTICA DO JOGO}

Podemos entender os esportes como conjunto de práticas corporais institucionalizadas mediante sua submissão a uma série de regras que tem por finalidade circunscrever, entre outras coisas, o tempo, o espaço e o ilícito da sua prática. Como elemento tipicamente moderno, sua regulamentação visava, também, a supressão do uso da violência física nas disputas, sinalizando o encaminhamento do processo civilizatório

\footnotetext{
${ }^{1}$ Apoio financeiro da FAPESP.
} 
observado em outros segmentos da sociedade da época. ${ }^{2}$ Assim, as investidas violentas bem como as expressões de agressividade adotadas como instrumento para a resolução de conflitos, ficavam circunscritas a um tempo-espaço próprio e contidas por regulamentações que as transfiguraram do aspecto físico para uma feição simbólica. ${ }^{3}$

As modificações empregadas nas manifestações pré-modernas do esporte implicaram, também, a produção de uma estética do movimento específica a qual adquire seu sentido no contexto ampliado do jogo. Portanto, longe de ser uma estética puramente formal, o corpo em movimento no esporte compõe um ato significativo na medida em que se coaduna com outros atos que aumentam as chances de êxito do atleta ou de sua equipe. Sua meta é a vitória. Logo se vê que os movimentos que integram as práticas esportivas modernas são teleologicamente orientados e sua execução não é desinteressada. É verdade que o grau de importância da vitória é relativo segundo o domínio ou forma de manifestação no qual a prática esportiva se insere e desenvolve, porém, não há dúvidas quanto a sua primazia no âmbito dos chamados esportes de rendimento, por vezes, em detrimento à experiência do corpo vivo do atleta no esporte na plenitude de "[...] suas singulares capacidades corporais e do imensurável alcance dessas experiências de autorrealização pessoal".4

Particularmente no futebol brasileiro de alto rendimento, a vitória converte-se em imperativo do jogo a partir da profissionalização dos atletas, processo que se inicia, entre os homens, por volta dos anos de 1930, consolidandose na segunda metade daquele século sob a influência da entrada do esporte na programação televisiva. Podemos assumir então que, desde esse período, entra em curso o processo de produção de uma sensibilidade estética específica, tanto do corpo do atleta que, cada vez mais precocemente, é tornado objeto de intervenção das variadas ciências tendo em vista sua potencialização para o rendimento, ${ }^{5}$ quanto do olhar da torcida, que se fascina com os lances de velocidade e com a resistência dos atletas a despeito de sua extenuação física.

\footnotetext{
${ }^{2}$ ELIAS; DUNNING. A busca da excitação, p. 199. ELIAS. O processo civilizador, p. 186.

${ }^{3}$ ELIAS; DUNNING. A busca da excitação. BOURDIEU. Questões de sociologia.

${ }^{4}$ BARREIRA. Estrutura e gestão do sistema esportivo brasileiro e o projeto ético-político da Psicologia do Esporte, p. 58.

${ }^{5}$ VIEIRA. Futebol não é (só) brincadeira: os processos de formação e subjetivação de atletas, p. 75.
} 
De acordo com Damo, a matriz ou configuração futebolística de alto rendimento sobrepõe-se as outras (futebol de bricolagem, futebol de várzea e futebol escolar), descaracterizando a diversidade de manifestações esportivas que tendem a ser reunidas sob o termo futebol. ${ }^{6}$ Com isso, privilegia-se uma forma estética dentre as inúmeras que são possíveis nesta modalidade nas suas variadas singularizações. É a esta matriz que se direciona o gosto do público brasileiro. Sua caracterização, segundo o autor, é definida pelo monopólio organizacional da FIFA, pela divisão social do trabalho (profissionais diretos - aqueles que interferem diretamente no jogo, seja dentro ou fora de campo; os especialistas - aqueles que, por meio das técnicas disponibilizadas por cada meio midiático, produzem narrativas que procuram ordenar o ritual em evento jornalístico; os torcedores) e pela exigência de excelência performática no uso das técnicas corporais. Kessler vem acrescentar ao argumento do autor que tal gosto também é modulado por um recorte de gênero, uma vez que a apreciação do público a esta forma de manifestação esportiva limita-se ao futebol desempenhado por homens, ${ }^{7}$ tal qual pode ser observado nas figuras a seguir.

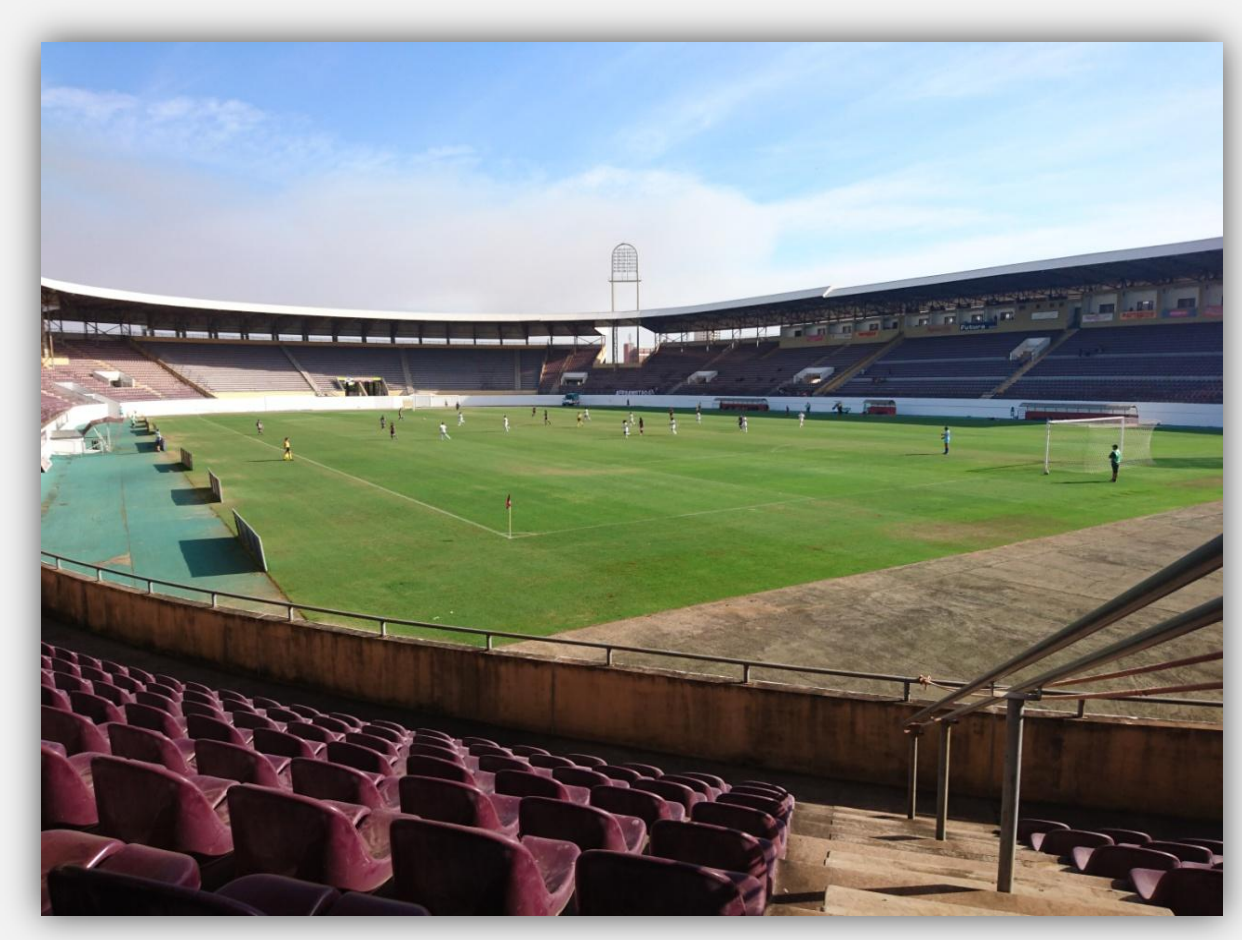

Fig. 1: Partida válida pelo Campeonato Brasileiro de Futebol Feminino de 2018. Fonte: Acervo pessoal - materiais de pesquisa.

\footnotetext{
${ }^{6}$ DAMO. Monopólio estético e diversidade configuracional no futebol brasileiro, p. 131.

${ }^{7}$ KESSLER. Futebol ou futebóis: é plural ou singular?, p. 27.
} 


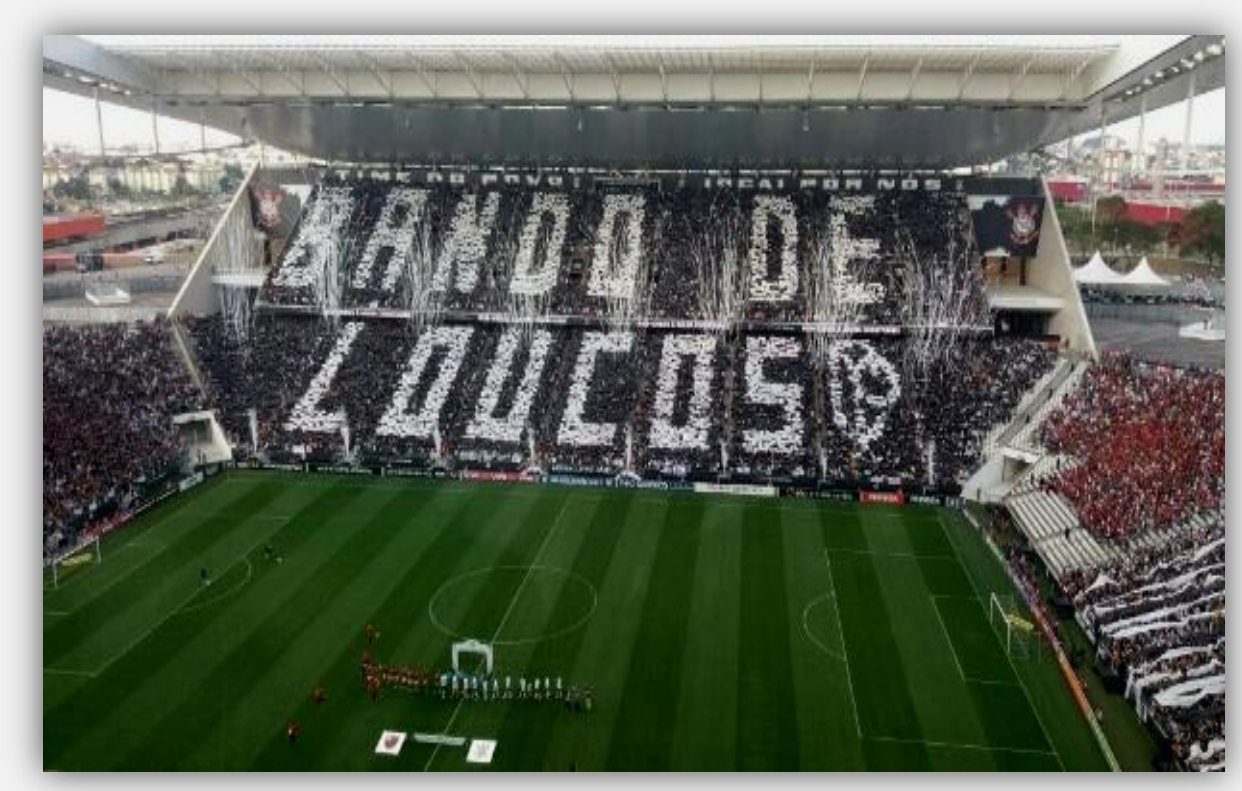

Fig. 2: Partida válida pelo Campeonato Brasileiro de Futebol Masculino em 2017. Fonte: http://bit.ly/2ESq308.

Ainda que as figuras não se refiram às equipes masculina e feminina dos mesmos clubes, retratam eventos que podem ser considerados grandes clássicos do futebol dentro de cada um dos campeonatos destacados. Na figura 1, o público total registrado foi de 23 pessoas, contando com membros da comissão técnica de uma das equipes que acompanharam o jogo da arquibancada. A entrada era gratuita, como de praxe nos certames do futebol protagonizado por mulheres. $\mathrm{Na}$ figura 2, o público de 44.682 pagantes, com valor do ingresso custando, em média, $\mathrm{R} \$ 90,00$, de acordo com o setor do estádio escolhido pelo torcedor.

Porém, como assevera Damo, a sensibilidade estética expressa pelo gosto do torcedor está longe de restringir-se ao aspecto unicamente formal do jogo. ${ }^{8}$ Assim, para o autor, o fascínio do público, ou da maior parte dele, que torce e se retorce nas arquibancadas (e mesmo nos sofás ou nas mesas de bar) não depende exclusivamente dos dribles desconcertantes, cujos variantes nominais são diversos (lençol, caneta, carretilha, lambreta), das trocas de passes bem executadas, das defesas improváveis ou daquela bola que, carinhosamente, é amortecida no peito e desliza com suavidade até o pé do jogador para a finalização decisiva. Na tentativa de precisar melhor e compreender os aspectos envolvidos no componente estético

\footnotetext{
${ }^{8}$ DAMO. Futebol e estética.
} 
que configuram o gosto do torcedor brasileiro, o autor apresentou e discutiu três categorias analíticas: o ritual disjuntivo, o pertencimento clubístico, o jogo absorvente, as quais exporemos a seguir.

A primeira categoria apontada é apresentada como componente estrutural do jogo na cultura ocidental. Segundo ele, o ritual disjuntivo levaria a produção de acontecimentos, uma realidade que finda na separação entre vencedores e perdedores. Assim, diferente de uma visão romântica sobre o futebol de outrora, que se caracteriza como evocação da "beleza do morto" e pela defesa da possibilidade de apreciação do gesto em si, o autor argumenta que o juízo estético que se faz sobre uma partida de futebol é profundamente afetado pelo resultado que "[...] influencia de tal modo a sensibilidade que acaba se tornando determinante". Ainda que não desconsidere a importância da imprevisibilidade que, ao proporcionar a experiência de graus de tensão variados, entre atletas e torcedores, no decorrer de uma partida, constitui um dos componentes centrais do espetáculo, o autor insiste na ideia de que não basta que os gestos sejam bem executados, exige-se deles certa eficácia "Cada movimento necessita produzir uma vantagem técnica sobre os adversários e isto configura uma relação de poder". ${ }^{9}$

A apreciação puramente formal seria reservada àqueles que não possuem familiaridade com o jogo, suas regras e sua dinâmica. Deste modo, atesta que "O prazer estético depende do entendimento da dinâmica do jogo, o que pressupõe aprendizado e, de outra parte, concordância em relação a alguns significados. Um desses significados partilhados pelos futebolistas é que o jogo é uma guerra mimética".10 Daí a compreensão do futebol como ritual disjuntivo e a importância do placar na avaliação do jogo. Nesta acepção de guerra, o jogo funciona como um meio de atualizar e afirmar uma infinidade de símbolos associados aos clubes do coração e também a um tipo específico de masculinidade (contatos físicos, por vezes violentos, agressividade verbal) reiterando a afirmação de Dunning de que o esporte se constituiu (e tende a reproduzir-se) como área de reserva masculina. ${ }^{11}$

\footnotetext{
${ }^{9}$ DAMO. Futebol e estética, p. 86.

${ }^{10}$ DAMO. Futebol e estética, p. 86

${ }^{11}$ DUNNING. O desporto como área masculina reservada: notas sobre os fundamentos sociais na identidade masculina e as suas transformações, p. 389.
} 
De modo complementar ao argumento apresentado, Neri Marinho afirma que ainda que o aspecto objetivo, formal e pragmático do jogo compareça na avaliação estética que se faz sobre ele, tal qualidade, no futebol, ultrapassa a dimensão estritamente física. Para o autor em tela:

A Estética do Futebol, não se esgota no objecto ou no sujeito, mas centraliza-se no que de significativo emana desta relação. Ela vagueia pela interacção apreciador/jogo, sujeito - objecto, atenta à qualidade que se faz sentir. Considera a experiência que nasce quando o jogo se torna significativo para o apreciador, quando nasce a experiência estética. ${ }^{12}$

A conversão do jogo em elemento significativo para o apreciador dialoga com aquilo que é exposto por Damo, na segunda categoria examinada em seu texto: o pertencimento clubístico. De acordo com ele, o pertencimento clubístico constitui-se numa das primeiras experiências de participação do sujeito na vida pública, fora dos domínios da casa e da família, ainda que a socialização primária na vivência do pertencimento ocorra, usualmente, em redes de sociabilidade próximas (família, amigos, vizinhos). 0 autor destaca que a rede responsável por essa socialização primária atua, também, na “[...] inculcação de certas sensibilidades emocionais" que tendem a permanecer vivas na lembrança do torcedor. ${ }^{13}$ Assim, a experiência do belo, no futebol, parece emergir do "[...] encontro estético entre o apreciador e o jogo",14 o qual só ganha possibilidades para ocorrer e se manifestar em um território compartilhado que é emoldurado a partir de traços culturais específicos. ${ }^{15}$

A escolha do time de futebol implica a demarcação de um dado posicionamento social e político que pode ser atestado na medida em que o pertencimento clubístico expressa e dá acesso a diversos conflitos subjacentes à dinâmica da sociedade. Não por ação do acaso os clubes brasileiros são identificados por meio de pares antagônicos como elite/popular, centro/periferia, branco/negro, democrático/autoritário. ${ }^{16}$ Aqui, encontramos mais um elemento em favor da concepção de que a estética futebolística brasileira ultrapassa uma perspectiva

\footnotetext{
${ }^{12}$ NERI MARINHO. Valor estético do futebol, p. 15.

${ }^{13}$ DAMO. Futebol e estética, p. 87.

${ }_{14}^{14}$ NERI MARINHO. Valor estético do futebol, p. 18.

${ }^{15} \mathrm{NERI}$ MARINHO. Valor estético do futebol, p. 17.

${ }^{16}$ DAMO. Futebol e estética.
} 
exclusivamente formal. Ao que parece, a apreciação acerca da beleza ou da feiura de um jogo também é balizada segundo o conflito traçado, considerando os símbolos referenciais que tendem a ser associados a cada uma das agremiações.

Por fim, o autor reúne os aspectos elucidados anteriormente na tentativa de localizar os elementos objetivos, ainda que não estritamente formais, que interferem na emissão de juízos estéticos sobre o futebol. Segundo ele, a composição entre o caráter de ritual disjuntivo, com as tensões decorrentes da imprevisibilidade que o embate enseja e o anseio pelo desfecho circunscrito a um tempo-espaço, e os elementos de pertencimento, que é marcado não só pelo amor a um clube, mas pela aversão a outro (aquele considerado seu contrário), sintetiza aquilo que haveria de mais fundamental na caracterização do jogo absorvente, aquele capaz de despertar o interesse do público e ser avaliado como um "bom jogo".

O jogo, considerado único, se apresenta como meio de disputa simbólica que possibilita afirmar-se sobre aqueles de pertencimento diverso, supremacia que se torna tanto mais valiosa quanto maior for à capacidade daquele jogo particular mobilizar e atualizar as tradições de rivalidade já instaladas entre as agremiações. Conforme afirma o autor:

Uma partida de futebol pode ser apreciada simplesmente pelo espetáculo que os jogadores proporcionam. Mas será mais espetacular ainda se puder identificar a trajetória dos atletas, a importância do jogo e a história dos clubes. Todavia, será plenamente espetacular para aqueles cujos jogadores e clubes pertencem. Um jogo poderá ser excitante mesmo que tecnicamente fraco, basta que a tradição lhe assegure uma posição de destaque, denominando-o "clássico". ${ }^{17}$

Assim, uma perspectiva estética sobre o futebol não considera apenas o nível técnico da partida. Sua apreensão, desde este olhar, é atravessada por histórias, memórias e tradições cuja elaboração ultrapassa o momento específico do jogo. Igualmente, envolve a vivência do espetáculo como uma experiência agonística entre símbolos e referências divergentes, da qual se pode sair vitorioso, reiterando sua superioridade sobre o adversário (e a comparação, aqui, não se restringe ao âmbito esportivo) ou, pelo contrário, perdedor, ocasião em que somos impelidos a reconhecer sua soberania sobre nós (ainda que não se aceite a derrota).

\footnotetext{
${ }^{17}$ DAMO. Futebol e estética, p. 89.
} 
Ainda que os elementos anteriores contribuam para que avancemos na compreensão estética do jogo e daquilo que o torna uma experiência palatável ao gosto de quem o assiste, resvalamos numa questão que parece ser de grande importância: a avaliação do jogo como "bonito" ou "belo", e que justificaria a adesão do público ao espetáculo, resultaria de uma percepção "natural" e automaticamente despertada pelo evento? De outro modo: haveria algo próprio do jogo que, atendendo aos aspectos formais, bem como aqueles levantados por Damo, levaria, invariavelmente, qualquer espectador a emitir uma apreciação sobre o espetáculo como um "jogo bonito", sendo, neste caso, a percepção um epifenômeno universal do conjunto de elementos abordados? Algumas pistas já esboçadas aqui, a partir das contribuições de Neri Marinho, ${ }^{18}$ nos abrem possibilidades para desdobrarmos esta questão que nos norteará na próxima seção.

\section{A PERCEPÇÃO E O HABITUS NA COMPOSIÇÃO DA EXPERIÊNCIA ESTÉTICA}

Desde uma perspectiva da Psicologia da Atenção, ${ }^{19}$ somos levados a recusar a ideia de uma percepção que se dê nos termos mencionados anteriormente. Um ponto aqui nos parece certo: para que eu possa elaborar um juízo sobre algo é necessário que ele se manifeste, que se apresente como objeto para mim, enfim, é preciso que eu o perceba. Porém, não é o objeto em si que, no transbordamento de um de seus aspectos, provoca em mim uma experiência estética a seu respeito. Do mesmo modo, não há um componente essencial, intrínseco e inerente a mim, que atua como determinante no juízo que faço sobre ele. A percepção não é atributo exclusivo e unidirecional nem do sujeito, nem do objeto. Ela é um ato intencional, na medida em que se refere a alguma coisa distinta de si mesma (eu percebo o copo sobre a mesa ou o vaso sobre o banco de madeira). Tais apontamentos parecem ser importantes para que possamos avançar em nosso debate sobre o tema do futebol praticado por mulheres a partir de uma perspectiva estética.

\footnotetext{
${ }^{18} \mathrm{NERI}$ MARINHO. Valor estético do futebol.

${ }^{19}$ RICOEUR. Escritos e conferências 3: antropologia filosófica.
} 
O problema da percepção se coloca, aqui, de modo relacional, em que o par, sujeito que percebe e objeto percebido, tem sua existência necessariamente ditada no âmbito do ato intencional. Sobre este ponto, Ricoeur é esclarecedor ao afirmar que "Perceber é conhecer objetos, o mundo. Quando percebo, não estou ocupado comigo, não conheço a mim. Estou fora de mim". ${ }^{20}$ Portanto, a percepção consiste na apreensão intencional daquilo que se apresenta, que se manifesta para mim (aquilo que se constitui em objeto para mim). No tocante a problemática suscitada neste texto, resta questionar se o futebol praticado por mulheres ascende ao estatuto de objeto para os torcedores. Neste ponto, não temos razões para recusar uma resposta afirmativa.

A discussão apresentada pelo autor a respeito do campo perceptivo total também parece contribuir para o presente texto, ao declarar que a clareza com que se percebe um objeto pode ser caracterizada por "[...] um fenômeno de contraste entre uma figura e um fundo". ${ }^{21}$ Desse modo, o objeto percebido destaca-se, ou melhor, vai adquirindo contornos mais definidos (ganhando clareza) na medida em que passa do segundo plano (fundo) para o primeiro (figura). Sobre este tema importa enfatizar que o objeto não é percebido por si mesmo, o seu destaque de um fundo implica a apreensão deste também. Figura e fundo nos são dados conjuntamente. A partir destas considerações, parece possível assumirmos que o fundo tem uma função estruturante na percepção do objeto. Percebemos um dado aspecto do objeto, e não outro, de acordo com o modo como o campo perceptivo está organizado e como nos relacionamos com ele. Isso não significa que o aspecto destacado seja o único. É a unidade de uma multiplicidade. Um dos inúmeros esboços que me é dado. ${ }^{22}$

O destaque do objeto ou de um de seus aspectos realça algo que já estava contido nele, não como preexistência potencial ou virtual, mas como elemento inexplorado no campo e que faço aparecer. Sobre isso, Ricoeur argumenta que o "fazer aparecer" não se restringe, necessariamente, a uma busca orientada por ideias constituídas a priori, não se trata de deparar-se com algo que eu já

\footnotetext{
${ }^{20}$ RICOEUR. Escritos e conferências 3, p. 45.

${ }^{21}$ RICOEUR. Escritos e conferências 3, p. 49.

${ }^{22}$ RICOEUR. Escritos e conferências 3.
} 
antecipava acerca o objeto. Antes, este ato refere-se a uma postura interrogativa ingênua, "[...] consiste em buscar uma inocência dos olhos e dos sentidos, uma abertura de espírito, um acolhimento ao outro em sua qualidade de outro". ${ }^{23}$ É o que o autor denomina "respeito ao objeto", postura por meio da qual se tornaria possível adentrar ao âmbito próprio do objeto, ao invés de simplesmente inseri-lo no campo de nossas experiências pregressas. A mudança de perspectiva não decorre de uma ação fortuita que se desdobra com o mero passar do tempo (ainda que este possa contribuir para tal alteração), mas demanda uma atitude interrogativa capaz de contemplar a referida ingenuidade que me torna disponível para o objeto e para apreendê-lo desde outros ângulos.

Como dito anteriormente, face aos argumentos apresentados, não temos razões para crer que o futebol praticado por mulheres não seja apreendido como objeto pelos torcedores. Eles o percebem. Mas, o que configura a percepção do objeto como experiência estética (ou como objeto estético)? Em se manifestando, como posso apreendê-lo não apenas como objeto, mas como objeto estético? Seria um atributo exclusivo do objeto? Tal hipótese parece não se sustentar, na medida em que a existência de uma obra de arte, por exemplo, não implica em percebê-la automaticamente como objeto estético.

Sobre este tema, vale introduzirmos algumas considerações feitas por Werle a propósito daquilo que ele denomina percepção estética no campo das artes “[...] o estético se coloca numa relação do homem com o mundo (das coisas), isto é, de que o fenômeno estético se realiza numa região intermediária ou intencional da relação do homem com o mundo". ${ }^{24}$ Com isso notamos que não se trata de defender a primazia nem do sujeito, nem do objeto, mas de buscar os elementos que constituem a experiência estética enquanto fenômeno. A discussão feita pelo autor recusa a ênfase em um único polo da experiência e defende que esta é marcada por uma circularidade que unifica sujeito e objeto no conceito de intencionalidade, deste modo "[...] o objeto estético não existe sem a percepção estética e vice-versa". ${ }^{25}$

\footnotetext{
${ }^{23}$ RICOEUR. Escritos e conferências 3, p. 57.

${ }^{24}$ WERLE. Mikel Dufrenne: a fenomenologia da experiência estética, p. 457.

${ }^{25}$ WERLE. Mikel Dufrenne: a fenomenologia da experiência estética, p. 458.
} 
De modo semelhante, levando o debate ao campo próprio do tema que trazemos, Neri Marinho afirma que “[...] a experiência estética não nasce de um encontro entre estranhos que nada significam para o outro, que nada sabem um do outro, que nada partilham. Sujeito e objecto, apreciador e jogo, têm uma história comum que os mistura, os entranha". ${ }^{26}$ Assim, segundo as pistas que temos seguido até o momento, entendemos que a avaliação e o juízo feito a respeito do futebol não decorre de elementos isolados e indiferentes entre si, mas parece haver uma necessária cumplicidade entre eles que culmina na apreciação de um jogo como belo.

À vista do que foi apresentado até o momento, nos resta questionar, considerando o problema levantado por este texto, a experiência estética da torcida de futebol em relação à prática deste esporte que, em relação à prática deste esporte que quando empreendida por mulheres, tende a ser qualificada como feia ou pouco atrativa. Os parágrafos precedentes parecem já ter trazido algumas contribuições importantes para avançarmos na discussão. Seria possível definirmos a postura da torcida, ao menos de parcela significativa dela, por uma falta de abertura ou de disponibilidade para apreensão desta outra manifestação do futebol? Não podemos recusar que as avaliações proferidas pelos torcedores expressam sensibilidades específicas no modo como eles são afetados pelo futebol. Tais sensibilidades não parecem se limitar ao âmbito das apreciações individuais, na medida em que são compartilhadas por grupos relativamente grandes (ainda que algumas variações sejam efetivamente encontradas entre os fãs deste esporte). Mesmo se este fosse o caso, soa pouco plausível a assunção de que indivíduos com preferências tão similares a respeito do futebol se encontraram, como que por ação do acaso, e decidiram se reunir como grupo torcedor. É neste ponto que o conceito de habitus, cunhado e desenvolvido por Pierre Bourdieu, parece trazer alguns feixes de luz sobre o problema.

O conceito de habitus elaborado por Bourdieu é múltiplo e se oferece como um valioso recurso para a leitura de distintos acontecimentos no tecido social. ${ }^{27}$ Sua vastidão ultrapassa nossas condições atuais para uma exploração ampla a seu

\footnotetext{
${ }^{26}$ NERI MARINHO. Valor estético do futebol, p. 18.

${ }^{27}$ BOURDIEU. Esboço de uma teoria da prática: precedido de três estudos sobre etnologia cabila.
} 
respeito e que faça jus a sua importância. Ainda assim, entendemos que ele pode trazer contribuições para o desenvolvimento deste artigo, mesmo que abordado de modo parcial e por meio de um recorte bastante específico. Aqui, adotaremos este conceito especialmente pelo que ele pode nos oferecer no que se refere à existência de uma certa matriz perceptiva, categoria que concorre para o entendimento daquilo que vimos chamando de sensibilidades estéticas ou gosto do torcedor de futebol.

Bourdieu apresenta o conceito de habitus como um sistema de disposições duráveis, uma estrutura estruturada em meio às condições sociais de existência do sujeito e que lhe é inculcada através de suas experiências na vida social e de modo não intencional, na medida em que elas são "[...] colectivamente orquestradas sem serem o produto da acção organizadora de um maestro de orquestra". ${ }^{28}$ Por outro lado, o habitus também atua como princípio gerador de práticas e, portanto, de produção da realidade. Dada à difusão dos meios que levam a sua produção, o habitus não se limita ao plano da consciência e tampouco a um produto da obediência de regras. ${ }^{29}$ Ele configura-se como princípio que orienta os modos de ser, pensar, agir e sentir dos sujeitos a despeito do domínio ou do acesso que estes tenham quanto às fontes ou raízes de suas condutas. Assim, entende o habitus como "[...] sistema de disposições inconscientes que constitui o produto da interiorização das estruturas objetivas". ${ }^{30}$

Por intermédio da formação do habitus a estrutura social induz à produção de aspirações e práticas compatíveis com suas exigências e suas condições objetivas. É importante destacar que tal conceito não se refere a um determinismo social, ainda que em distintos momentos da discussão apresentada pelo autor ele pareça habitar uma zona fronteiriça com esse conjunto de ideias. Seu distanciamento em relação a tal perspectiva se torna evidente pela insistência do autor na afirmação de uma relação dialética entre indivíduo e sociedade (dicotomia que passa a ser recusada em sua teoria a partir do conceito ora abordado), identificada por ele no movimento de interiorização da exterioridade e

\footnotetext{
${ }^{28}$ BOURDIEU. Esboço de uma teoria da prática, p. 164.

${ }^{29}$ BOURDIEU. Esboço de uma teoria da prática.

${ }^{30}$ BOURDIEU. A economia das trocas simbólicas, p. 201.
} 
de exteriorização da interioridade, o qual seria responsável, entre outras coisas, por estabelecer a continuidade entre as gerações.

Conforme Setton também são frequentes as críticas ao conceito de habitus alegando que este se funda exclusivamente no princípio da reprodução das estruturas. ${ }^{31} 0$ próprio Bourdieu atesta o caráter estabilizador do habitus e sua tendência à reprodução e conservação, quando afirma, por exemplo, que ele “[...] tende a reproduzir as regularidades imanentes às condições objectivas da produção do seu princípio gerador". ${ }^{32}$ A inculcação das estruturas sociais é efetuada de tal modo que atinge um grau de enraizamento em nossas condutas, modos de pensamento, percepção e julgamento que ultrapassa o plano consciente, de maneira que a conscientização acerca das condições de produção do habitus não assegura sua modificação. Assim, padrões de cunho racista, machista e lgbtfóbico, por exemplo, podem irromper em ações e avaliações cotidianas a despeito de nossa consciência das opressões que tais sistemas embasam, difundindo e legitimando as mais variadas formas de violência física e simbólica. Uma mulher, por exemplo, ainda que seja consciente das opressões que se lhe foram impostas, pode sentir-se culpada após uma situação em que tenha exercido seus direitos de liberdade sexual ao engajar-se em atividades sexuais com distintos parceiros em curto período de tempo.

Porém, o autor afirma que o habitus também é dotado de uma porosidade que lhe possibilita ajustar-se "[...] às exigências inscritas a título de potencialidades objectivas na situação diretamente enfrentada". 33 Cabral destaca aquilo que denomina "teatro como pedagogia" para enfatizar o papel da pedagogia crítica e da ação cultural, reunidas e operadas por intermédio do teatro, no processo de transformação do habitus. ${ }^{34}$ Segundo a autora, tal recurso contribui para a ampliação das formas de percepção e para a modificação de ações cotidianas reprodutoras de lógicas e práticas sociais que constrangem a dignidade de pessoas e grupos diversos. Aqui, o teatro parece funcionar como recurso que, por meio de uma ação simulada, evoca situações que expressam os modos instituídos de

\footnotetext{
${ }^{31}$ SETTON. A teoria do habitus em Pierre Bourdieu: uma leitura contemporânea.

${ }^{32}$ BOURDIEU. Esboço de uma teoria da prática, p. 168.

${ }^{33}$ BOURDIEU. Esboço de uma teoria da prática, p. 168.

${ }^{34}$ CABRAL. Ação cultural e teatro como pedagogia.
} 
perceber e agir a respeito de determinados temas, promovendo sua confrontação a partir de outras perspectivas possíveis. Assim, a prática emerge como lócus privilegiado da relativização e eventual atualização do habitus uma vez que promove seu confronto com as especificidades de uma situação particular, argumento que pode ser sustentado a partir da fala de Bourdieu quando afirma:

A prática é ao mesmo tempo necessária e relativamente autónoma por referência à situação considerada na sua imediatez pontual porque é o produto da relação dialéctica entre uma situação e um habitus, entendido como sistema de disposições duradouras e transponíveis que, integrando todas as experiências passadas, funciona a cada momento como matriz de percepções, de apreciações e de acções, e torna possível efectuar de tarefas infinitamente diferenciadas graças às transferências analógicas de esquemas que permitem resolver os problemas da mesma forma e graças às mesmas correcções incessantes dos resultados obtidos, dialecticamente produzidas por esses mesmos resultados. ${ }^{35}$

A autonomia da situação imediata se dá em virtude da necessidade de que haja uma mobilização prática do passado, mas, igualmente, essa prática sofre os efeitos dos resultados que produz, levando-a a ajustes e correções. Portanto, as práticas que o habitus produz não podem ser integralmente dedutíveis nem das condições objetivas imediatas, nem das condições que o forjaram como princípio estável, mas apenas se considerarmos a relação entre a estrutura de produção do habitus e a conjuntura na qual ele se manifesta. ${ }^{36}$

0 excerto anterior traz de maneira explicita o entendimento do habitus como uma matriz perceptiva, moldada a partir do conjunto de experiências do sujeito no campo social. Neste ponto, parece oportuno introduzirmos a questão do gosto que, conforme a argumentação que vimos traçando, encontra-se relacionada ao habitus. Segundo Alves, o habitus tem papel fundamental na definição de um gosto, uma vez que as preferências manifestadas por um agente social se relacionam às condições sociais de existência. Afirma que "Os agentes apreendem os objetos ofertados simbolicamente através dos esquemas de percepção e de apreciação de seus habitus" ${ }^{37}$ A apreciação estética parece, então, resvalar-se nas condições sociais de produção desses sistemas de disposições duráveis e

\footnotetext{
${ }^{35}$ BOURDIEU. Esboço de uma teoria da prática, p. 167.

${ }^{36}$ SETTON. A teoria do habitus em Pierre Bourdieu. BOURDIEU. Esboço de uma teoria da prática.

${ }^{37}$ ALVES. Pierre Bourdieu: a distinção de um legado de práticas e valores culturais, p. 4.
} 
internalizados, sendo inicialmente definida por intermédio delas (ainda que não esteja fadada a manter-se nesses moldes). Tal afirmação pode ser depreendida de Bourdieu quando este assinala que “[...] a obra de arte só adquire sentido e só tem interesse para quem é dotado do código segundo o qual ela é codificada". ${ }^{38}$ Nestes termos, o gosto resultaria de condições específicas de socialização, marcadas, entre outras coisas, pelas diferenças de origem e de oportunidades sociais dos sujeitos. Não sendo inato, a educação tem um papel fundamental na produção do gosto, mesma razão pela qual sua modulação é possível. ${ }^{39}$

É sabido, desde as elaborações publicadas por Dunning, ${ }^{40}$ que o esporte moderno, sobretudo nas modalidades ditas de confronto, se convencionou a ser tomado como espaço de reserva masculina, em que a sociedade não só admitia como também exaltava as manifestações desabridas de uma masculinidade hegemônica tradicional, pautada em elementos como a agressividade, a virilidade, a violência e as disputas de força e velocidade. Em face de uma sociedade cada vez mais civilizada, em termos de desaprovação do uso e incentivo da violência física, os esportes mantiveram a possibilidade de expressão deste tipo de masculinidade, ao mesmo tempo em que eram vistos como meio para o desenvolvimento do caráter de meninos e jovens segundo esses padrões.

Tais aspectos não se limitam apenas ao âmbito da prática desportiva direta, podendo ser igualmente observados como códigos referenciais reproduzidos entre as torcidas, como notamos por meio de análises sociológicas dedicadas ao exame do fenômeno da violência no desporto em geral ${ }^{41}$ e, de modo específico, do hooliganismo no futebol. ${ }^{42}$ Ainda que não possamos, neste momento, nos dedicar ao escrutínio pormenorizado destas questões, elas nos fornecem uma perspectiva geral e inicial acerca do amálgama que parece haver entre a formação do habitus do torcedor de futebol e o conjunto de valores de um tipo de masculinidade

\footnotetext{
${ }^{38}$ BOURDIEU. A distinção: crítica social do julgamento, p. 10.

${ }^{39}$ FARIAS; COSTA. Ensaio sobre o 'gosto' em Theodor W. Adorno e Pierre Bourdieu.

${ }^{40}$ DUNNING. O desporto como área masculina reservada: notas sobre os fundamentos sociais na identidade masculina e as suas transformações.

${ }^{41}$ DUNNING. O desporto como área masculina reservada: notas sobre os fundamentos sociais na identidade masculina e as suas transformações.

${ }^{42}$ DUNNING, MURPHY \& WILLIANS. A violência dos espectadores nos desafios de futebol: para uma explicação sociológica, p. 355.
} 
(segundo uma idealização sociocultural enrijecida do masculino e do ser homem assentada nas noções de virilidade e agressividade).

Esses valores, projetados sobre os que protagonizam o espetáculo, exigem um suporte corporal específico para seu acolhimento, a fim de assegurar ou ampliar as possibilidades de uma identificação entre os torcedores e os gladiadores da bola. Assumindo a existência de uma relação de identidade entre público e jogo, este passaria a ser visto como seu espelho de tal modo que "O que o público deseja, seguidamente, é ver naqueles que supostamente o representam, atributos compatíveis com aquilo que acreditam ou gostaria de ser. Assim se moldam os estilos nacionais, mas também os regionais, locais e clubísticos". ${ }^{43}$ Nestes termos, evidenciamos o papel que os olhares (e expectativas) do público têm na formatação dos estilos e formas de jogo, fazendo com que se dê maior vazão e se estimule a produção de um tipo particular de futebol, contribuindo para reforçar o caráter estabilizador do habitus e, por conseguinte, do gosto do apreciador do jogo.

\section{FUTEBOL DE MULHERES: HABITUS, GÊNERO E A PERCEPÇÃO ESTÉTICA DO ESPORTE}

O habitus esportivo, particularmente o futebolístico, no caso do Brasil, revela também a presença de um habitus de gênero que prevê a designação diferencial de papeis sociais para os seres humanos, sobretudo com base na morfologia do órgão sexual. Neste quadro, a prática do futebol é vista como incompatível com a 'natureza feminina' e, portanto, contraindicada às mulheres de modo geral. Em que pesem as mudanças que podemos observar sobre o tema na atualidade, é imprescindível destacar que tal contraindicação assumiu forma jurídica na década 1940, quando da promulgação da primeira legislação esportiva do país.

O Decreto-Lei 3.199 de 1941 trazia no artigo 54 a seguinte determinação “Às mulheres não se permitirá a prática de desportos incompatíveis com as condições de sua natureza, devendo, para este efeito, o Conselho Nacional de Desportos baixar as necessárias instruções às entidades desportivas do país". ${ }^{4}$

${ }^{43}$ DAMO. O futebol e suas propriedades estéticas: estilo, tempo e espaço em perspectiva antropológica, p. 193.

${ }^{44}$ BRASIL. Decreto-Lei no 3.199, de 14 de abril de 1941. 
Ainda que a especificação das modalidades vetadas só tenha sido publicada anos mais tarde, ${ }^{45}$ o futebol esteve, desde o início, entre as práticas esportivas coibidas e perseguidas pela lei, pela ciência e pela opinião pública. ${ }^{46}$ Tal proibição, ao apelar para a ordem da natureza, camufla as condições sociopolíticas de sua produção, descaracterizando seu caráter de fenômeno historicamente situado e contribuindo para que ele continue sendo apreendido desde um olhar natural e biologizante. Aqui, é de grande valor a fala de Bourdieu ao afirmar que o habitus "[...] é história feita natureza [...] o 'inconsciente' nunca é, com efeito, senão o esquecimento da história que a própria história provoca incorporando as estruturas objectivas que produz nessas quase natureza que os habitus são". 47

Assim, as categorias envolvidas na composição estética do futebol, ${ }^{48}$ bem como os referentes integrantes do habitus do torcedor parecem despontar como instrumentos valiosos para que nos defrontemos com as explicações tautológicas que por vezes se esboçam acerca do o insucesso do futebol praticado por mulheres entre os torcedores brasileiros. Tal discussão torna patente o fato de que "[...] a teia de forças de uma cultura, o traço cultural que identifica e singulariza a cultura, presente em cada membro, integrando-o nessa cultura, torna-se numa lente pela qual se vê e se sente, por vezes, esteticamente, o mundo. E também o Futebol" ${ }^{49}$

Ora, que seriam as categorias apresentadas por Damo, em "Futebol e estética", senão componentes de um fundo (que definem e instituem uma tradição cultural) a partir do qual se destaca o espetáculo futebol? Ainda, quais seriam as chances (reais) da modalidade, quando praticada pelas mulheres, contar com a adesão das torcidas, considerando as condições (e valores) sociais que produzem o habitus do torcedor e que tendem a ser reproduzidas e reificadas nas práticas que este sistema de disposições tende a mobilizar?

Conforme argumentamos, a mudança exige um efetivo agir, um movimentarse no sentido de provocá-la, uma atividade no âmbito da prática em termos bourdieusianos. No caso explorado pelo texto, entendemos que existam duas frentes

\footnotetext{
${ }^{45}$ BRASIL. Deliberação № 7-65, de 02 de agosto de 1965.

${ }^{46}$ GOELLNER. Mulheres e futebol no Brasil: entre sombras e visibilidades.

${ }^{47}$ BOURDIEU. Esboço de uma teoria da prática, p. 168.

${ }^{48}$ DAMO. Futebol e estética.

${ }^{49}$ NERI MARINHO. Valor estético do futebol, p. 19.
} 
prioritárias de ação. De um lado, temos a necessária atuação dos órgãos de gestão do futebol nacional, na medida em que reconheçam o interesse em fazer do futebol de mulheres uma tradição inventad ${ }^{50}$ aprazível ao público brasileiro. De outro, urge o esforço em difundir as implicações da socialização generificada e a adoção de práticas pedagógicas, nos mais diversos âmbitos da educação (formal e não formal), que possam contribuir para a desnaturalização da arbitrariedade cultural que define o futebol como esporte de meninos e homens. Assim, defendemos que o futebol praticado por mulheres não evoca, por si mesmo, uma experiência estética desagradável. Pelo contrário, convoca a ampliação das sensibilidades do público torcedor para acolher outras formas de manifestação deste esporte.

\section{REFERÊNCIAS}

ALVES, Emiliano Rivello. Pierre Bourdieu: a distinção de um legado de práticas e valores culturais. Sociedade e Estado, Brasília, v. 23, n. 1, p. 179184, jan.-abr., 2008.

BARREIRA, Cristiano Roque Antunes. Estrutura e gestão do sistema esportivo brasileiro e o projeto ético-político da Psicologia do Esporte. Conselho Regional de Psicologia de São Paulo - Psicologia do Esporte: contribuições para a atuação profissional, p. 56-60, São Paulo: CRP-SP, 2016.

BOURDIEU, Pierre. A economia das trocas simbólicas. São Paulo: Perspectiva, 1974.

BOURDIEU, Pierre. Como é possível ser esportivo?. Questões de Sociologia. Rio de Janeiro, Marco Zero, 1983, p. 136-53.

BOURDIEU, Pierre. Esboço de uma teoria da prática - precedido de três estudos sobre etnologia cabila. Oeiras: Celta, 2002.

BOURDIEU, Pierre. A distinção: crítica social do julgamento. Trad. Daniela Kern; Guilherme J. F. Teixeira. São Paulo: Edusp; Porto Alegre: Zouk, 2007.

${ }^{50}$ HOBSBAWM. A invenção das tradições, p. 9. 
BRASIL. Decreto-Lei no 3.199, de 14 de abril de 1941. Estabelece as bases de organização dos desportos em todo o país. Rio de Janeiro, RJ, 1941.

BRASIL. Deliberação n 7-65, de 02 de agosto de 1965. Baixa instruções às entidades esportivas do país sobre a prática de desportos pelas mulheres. Brasília, DF, 1965.

CABRAL, Beatriz Angela Vieira. Ação cultural e teatro como pedagogia. Em Pauta, v. 12, n.1, p. 4.17, jun., 2012.

DAMO, Arlei Sander. Futebol e estética. São Paulo em Perspectiva, v. 15, n. 3, p. 82-91, 2001.

DAMO, Arlei Sander. Monopólio estético e diversidade configuracional no futebol brasileiro. Movimento: Revista de Educação Física da UFRGS, Porto Alegre, v. 9, n. 2, p. 129-156, maio-ago., 2003.

DAMO, Arlei Sander. O futebol e suas propriedades estéticas: estilo, tempo e espaço em perspectiva antropológica. Estudos de Sociologia: Revista do Programa de Pós-Graduação em Sociologia da UFPE, Recife, v. 14, n. 2, p. 157-198, 2008.

DUNNING, Eric. As ligações sociais e a violência no desporto. In: ELIAS, Norbert; DUNNING, Eric. A busca da excitação. Trad. Maria Manuela Almeida e Silva. Lisboa: Difel, 1992, p. 327-354.

DUNNING, Eric. O desporto como uma área masculina reservada: notas sobre os fundamentos sociais na identidade masculina e suas transformações. In: ELIAS, N.; DUNNING, E. A busca da excitação. Trad. Maria Manuela Almeida e Silva. Lisboa: Difel, 1992, p. 389-412.

DUNNING, Eric; MURPHY, Patrick; WILLIAMS, John. A violência dos espectadores nos desafios de futebol: para uma explicação sociológica. In: ELIAS, Norbert; DUNNING, Eric. A busca da excitação. Trad. Maria Manuela Almeida e Silva. Lisboa: Difel, 1992, p. 355- 388.

ELIAS, Norbert. O processo civilizador: formação do Estado e civilização. Rio de Janeiro: Jorge Zahar, 1993.

ELIAS, Norbert; DUNNING, Eric. A busca da excitação. Trad. Maria Manuela Almeida e Silva. Lisboa: Difel, 1992.

FARIAS, Tássio Ricelly Pinto; COSTA, Jean Henrique. Ensaio sobre o 'gosto' em Theodor W. Adorno e Pierre Bourdieu. Acta Scientiarum - Human and Social Sciences, Maringá, v. 37, v. 1, p. 93-101, jan.-jun., 2015.

GOELLNER, Silvana Vilodre. Mulheres e futebol no Brasil: entre sombras e visibilidades. Revista Brasileira de Educação Física e Esporte, São Paulo, v. 19, n. 2, p. 143-51, 2005.

HOBSBAWM, Eric. Introdução: a invenção das tradições. In: HOBSBAWM, Eric; RANGER, Terence (Orgs.). A invenção das tradições. Rio de Janeiro: Paz e Terra, 1984, p. 9-23. 
KESSLER, Cláudia Samuel. Futebol ou futebóis: é plural ou singular? In: . (Org.) Mulheres na área: gênero, diversidades e inserções no futebol. Editora UFRGS, 2016, p. 21-41.

NERI MARINHO, Daniel Jorge. Valor estético do futebol: o olhar do apreciador com conhecimento profundo do jogo. Dissertação (Licenciatura em Desporto e Educação Física). Universidade do Porto, Faculdade de Desporto, Porto, 2007.

RICOUER, Paul. Escritos e conferências 3: antropologia filosófica. Trad. Lara Christina de Malimpensa. São Paulo: Edições Loyola, 2016.

SETTON, Maria da Graça Jacintho. A teoria do habitus em Pierre Bourdieu: uma leitura contemporânea. Revista Brasileira de Educação, n. 20, p. 60-70, maio-jun.-ago., 2002.

VIEIRA, Talita Machado. Futebol não é (só) brincadeira: os processos de formação e subjetivação de atletas. Dissertação (Mestrado em Psicologia). Universidade Estadual Paulista, Faculdade de Ciências e Letras, Assis, 2017.

WERLE, Marco Aurélio. Mikel Dufrenne: a fenomenologia da experiência estética. Sapere Aude, Belo Horizonte, v. 6, n. 12, p. 456-464, jul.-dez., 2015. 